\title{
SOLVENT SELECTION FOR CHEMICAL REACTIONS: AUTOMATED COMPUTATIONAL SCREENING OF SOLVENTS USING THE SMD MODEL
}

\author{
Ellen V. Dalessandro and Josefredo R. Pliego Jr.* \\ Departamento de Ciências Naturais, Universidade Federal de São João del-Rei, 36301-160 São João del-Rei - MG, Brasil
}

Recebido em 16/01/2018; aceito em 15/03/2018; publicado na web em 02/04/2018

\begin{abstract}
Finding the most efficient solvent for a chemical reaction can demand costly experimental procedure and the screening is usually limited to few solvents. The use of theoretical methods could accelerate the search for the best solvent, able to promote most effective kinetics and thermodynamics of a reaction. In this work, it was proposed an automated procedure that calculates the solvent effect for a chemical reaction using all the 179 solvents available in SMD (solvation model density). The reaction of 2-bromoacetophenone with pyridine was used as a test. The SMD model correctly predicts the reactivity trends for five solvents, which experimental data are available. We have found that sulfolane, a less usual solvent, is the best one for this reaction. The present study points out that computational screening of large set of solvents using the SMD model is a viable approach and could be useful for chemical reactions optimization.
\end{abstract}

Keywords: solvent effect; nucleophilic substitution; Menshutkin reaction; continuum solvation model.

\section{INTRODUCTION}

Solvent effects on chemical reactions is a classical topic in chemistry and its understand is useful in the planning of reactions. ${ }^{1}$ In fact, simple rules discussed in organic chemistry textbooks have been devised to auxiliary in the prediction of solvent effect. Nevertheless, this qualitative and chemical intuition based approach is not enough for solvent selection from a large set of possible solvents. The need for reliable and quantitative methods for solvent selection in diverse applications has induced the development of several approaches, in some cases including green chemistry considerations..$^{2-10}$

The solvent can alter both the free energy of reaction $(\Delta \mathrm{G})$ and the free energy of activation $\left(\Delta \mathrm{G}^{\ddagger}\right)$ for each reaction step. Thus, for reactions with very negative free energy of reaction, the activation barrier determines the reaction time, product ratio (selectivity) and yield of a chemical reaction. In this case, the solvent effect on the free energy of activation is the critical property to analyze. Otherwise, if the free energy of reaction is close to zero, the thermodynamics of the reaction becomes important and can determine the selectivity and yield. ${ }^{11-15}$ This second case points out the important role of solvent for the stability of the products and this feature must be taken in account. A general view of the solvent effect on the Gibbs free energy profile of a chemical reaction is presented in Figure 1.

Usually, in the investigation of new reactions or synthetic procedures, several solvents are tested to find the most effective one. Nevertheless, the experimental screening is time-consuming, costly and limited to small number of solvents. It would be worth to have available theoretical methods able to make fast selection of the best solvent to conduct the reaction.

Inclusion of the solvent effect in theoretical calculations of chemical reactions has two main approaches: a) liquid simulation by molecular dynamics or Monte Carlo methods, ${ }^{16-18}$ and b) dielectric continuum-based models. ${ }^{19-32}$ The latter approach is especially useful for computational screening of solvents. Among the possible continuum methods, the SMD model of Cramer and Truhlar has been tested on several problems involving solvation and chemical reactions and usually presents a good performance for solvation of

*e-mail: pliego@ufsj.edu.br

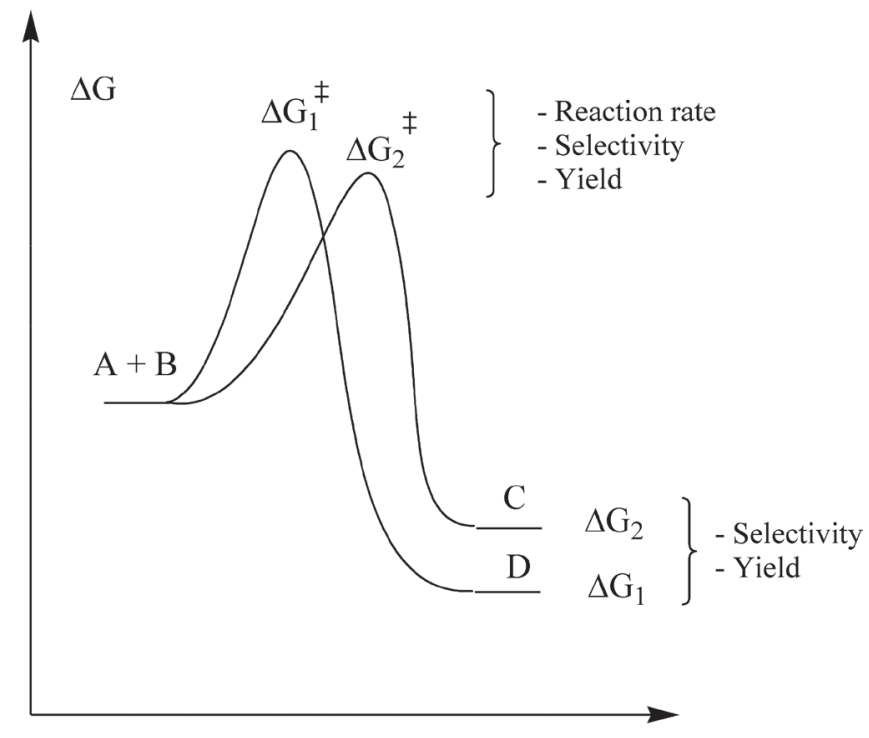

Figure 1. Gibbs free energy profile and its consequence on the reaction rate, selectivity and yield. This is a hypothetical profile

neutral species. ${ }^{24,33-38}$ In the cases that free ionic species are involved, the method is less reliable and may be needed to use hybrid clustercontinuum approaches. . $^{39,40}$

In the application of continuum models for chemical reactions, it is important to take care about the type of reaction is being considered. Scheme 1 present some cases. In the reactions of type (1), there is not free solvated ions involved and the SMD model is accurate. In fact, the error in the solvation free energy for the SMD model for neutral molecules is usually less than $1 \mathrm{kcal} \mathrm{mol}^{-1} .{ }^{24,37,38}$ In the second set of reactions, ions exist like ion pairs and ion pairs are being formed or are reacting. In addition, in the reaction (4), a free solvated ion is reacting with a neutral molecule and forming a new solvated ion and a new neutral molecule. This is a typical ion-molecule $\mathrm{S}_{\mathrm{N}} 2$ reaction and a substantial solvent effect takes place. For these cases, the SMD model is less reliable because this solvation model is less accurate for ion solvation. ${ }^{24,35,36}$ In addition, it is important to emphasize that only polar solvents can have free solvated ions in solution. The fifth 


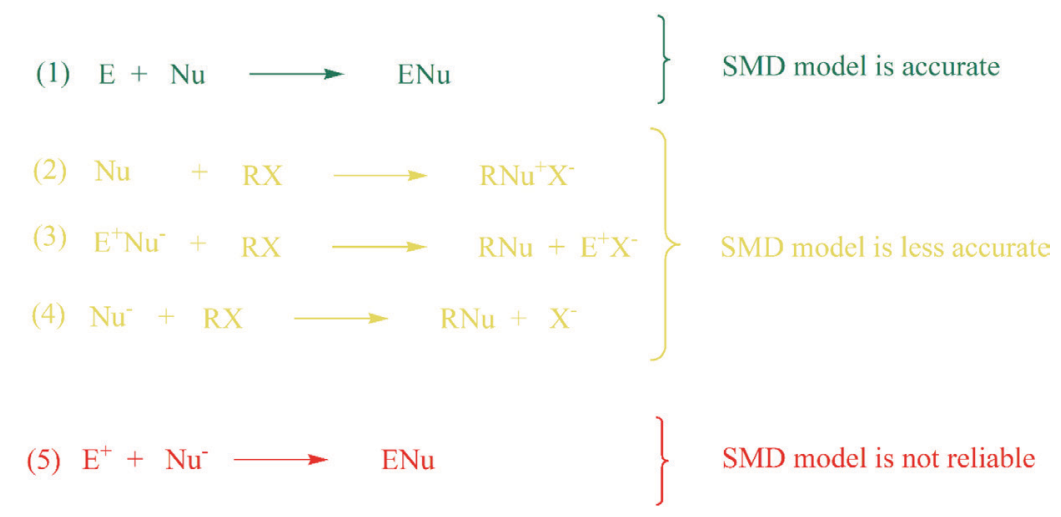

Scheme 1. Some types of reactions and how reliable is the SMD model

reaction is the most difficult case, because a pair of ions are forming a neutral species (or the reverse reaction). Continuum models may be very unreliable for this type of reactions. ${ }^{35}$

Recently, Struebing et al. have proposed a method based on quantum mechanics calculations and computer-aided molecular design (CAMD) to make a screening in a space of 1341 solvents. ${ }^{41,42}$ Their approach is a combination of continuum solvation calculation, using the SMD model for five or six solvents, ${ }^{41}$ and the solvatochromic equation in conjunction with group-contribution methods to predict the solvent effect for a large set of solvents. However, the procedure was not widely tested to predict solvation free energy of neutral and ionic solutes as the SMD model was, ${ }^{24,33,35,37}$ and the diversity of solvents is rather limited. For example, analyzing the group contribution scheme used by Struebing et al., it can be observed that it does not include sulfone, sulfoxide and amide groups. It would be desirable a solvent screening with a wider diversity of functional groups.

Struebing et al. have applied the CAMD method to investigate the solvent effect on a Menshutkin reaction (Scheme 2). They have found that the nitromethane is the best solvent. Thus, our goal in this work was to evaluate the CAMD method against full SMD calculations. The idea is using the high computational capabilities of modern workstations to show that direct automated SMD calculations for all the solvents of the SMD model can also be a viable and useful strategy for solvent selection.<smiles>O=C(CBr)c1ccccc1</smiles>

Scheme 2. Menshutkin reaction studied in this work

\section{THEORETICAL METHODS}

\section{Electronic structure calculations}

The reaction in Scheme 2 was investigated by quantum chemistry calculations, using the X3LYP functional ${ }^{43}$ and the $6-31(+) \mathrm{G}(\mathrm{d})$ basis set for geometry optimization and frequency calculations. The PCM method was used in these optimizations with the methanol solvent and atomic cavities with 240 tesserae to generate an accurate and continuous potential of mean force surface. ${ }^{44,45}$ The inclusion of the solvent in the optimizations provides more reliable geometries of the highly polar transition state. The use of other polar solvent hardly alters the geometries.

On the optimized structures, it was done single point energy calculations using the M08-HX functional ${ }^{46}$ and the def2-TZVPP basis set ${ }^{47}$ augment with diffuse functions on oxygen, nitrogen and bromine, a basis set similar to ma-def2-TZVPP. ${ }^{48}$ This higher level of theory was used to obtain the final electronic energy. It is worth to mention that this functional was tested for chemical reactions and provides reliable activation barriers. ${ }^{49}$

In the calculation of the solvation free energy, it was done single point calculation with the SMD method and the X3LYP/6-31(+)G(d) electronic density (IEFPCM for electrostatic part). The SMD model has parameters for 179 solvents. Thus, the SMD calculations were done for all the solvents via an automated procedure, using a python code (SNAPY) able to generate the input, run the quantum chemistry program and read the output. ${ }^{50,51}$ These SMD calculations have taken only $2000 \mathrm{~min}$ into 8 nuclei intel XEON processor. The standard state of $1 \mathrm{~mol} \mathrm{~L}^{-1}$ was used in the final report of the free energies. All of these calculations were done with the GAMESS program..$^{52,53}$

\section{SNAPY program}

The SNAPY program was written in the Python language and has the purpose of automating the assembly of input files and the reading of the output files in the solvation free energy calculations for all the 179 solvents parameterized for the SMD model. Because modern workstations are very fast, the preparation of the input files and the reading the output files is very time consuming. Thus, using the automation in the SNAPY, the time for the calculations may become less than $1 \%$ of the time spent without the use of the program.

The Program is divided in two parts. In the first part, the program reads the optimized geometry in the output file of GAMESS and selects the located geometry. Otherwise, the geometry previously obtained can be used as input. In the following step, these coordinates are used to generate 179 input files for each solvent available in the SMD. Then, the GAMESS program is carried out for each generated input file. After all the solvation calculations were carried out, the second part of the program reads the output files and generates a list of the solvation free energies obtained by the calculations for each solvent. These data can be read in the Excel to calculate the free energy of reaction and activation for each solvent. A scheme presenting how the program works is shown in Scheme 3. The python code (SNAPY) is available for any researcher interested to use the approach. ${ }^{51}$

\section{Kinetics analysis}

The rate constant $\mathrm{k}(\mathrm{T})$ for a chemical reaction is related to the free energy of activation through the Eyring equation:

$$
k(T)=\frac{k_{b} T}{h} e^{-\Delta G^{\ddagger} / R T}
$$

where $\mathrm{k}_{\mathrm{b}}$ is the Boltzmann constant, $\mathrm{h}$ the Planck constant and $\mathrm{R}$ the ideal gas constant. The free energy of activation in liquid phase 


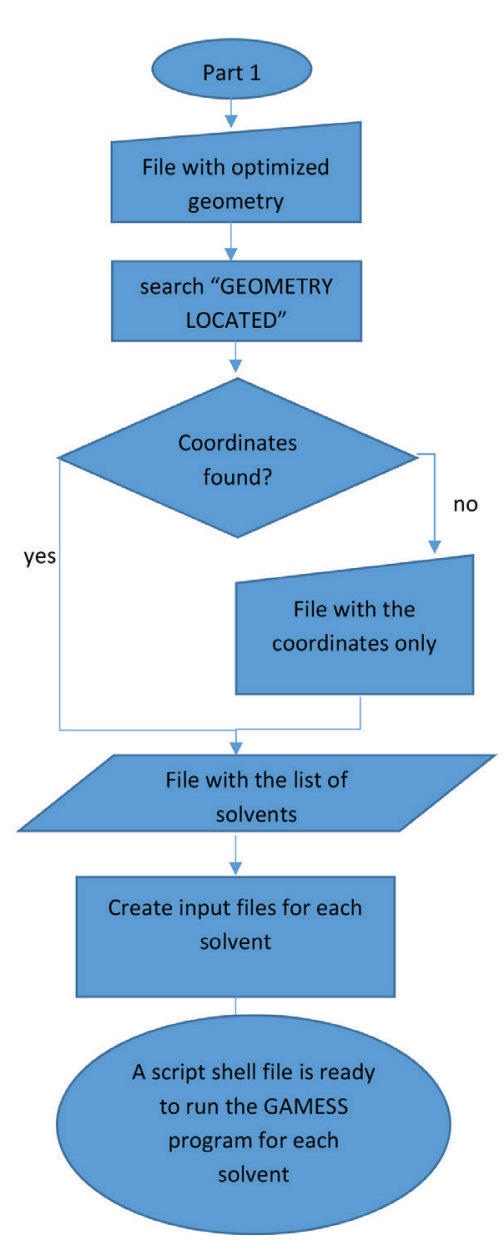

Scheme 3. Diagram showing how the SNAPY program works

$\left(\Delta G^{\ddagger}\right.$ ) has two contributions: the gas phase free energy $\left(\Delta G_{g}^{\ddagger}\right)$ and the solvation contribution to the free energy $\left(\Delta \Delta G_{\text {solv }}^{\ddagger}\right)$ :

$$
\Delta G^{\ddagger}=\Delta G_{g}^{\ddagger}+\Delta \Delta G_{s o l v}^{\ddagger}
$$

Because the reaction is bimolecular, and considering negative reaction free energy, the integrated rate law is given by:

$$
\ln \left(\frac{[B][A]_{0}}{[B]_{0}[A]}\right)=\left([B]_{0}-[A]_{0}\right) \cdot k t
$$

where $[\mathrm{A}]_{0}$ and $[\mathrm{B}]_{0}$ are the initial concentrations of the reactants $\mathrm{A}$ and $\mathrm{B}, \mathrm{k}$ the rate constant and $\mathrm{t}$ the reaction time. This equation considers $[\mathrm{A}]_{0} \neq[\mathrm{B}]_{0}$.

\section{RESULTS AND DISCUSSION}

The optimized transition state and ion pair product are shown in Figure 2. The gas phase contribution to the free energy of activation is $29.3 \mathrm{kcal} \mathrm{mol}^{-1}$, whereas the free energy of the product is $9.0 \mathrm{kcal} \mathrm{mol}^{-1}$ above of the reactants. Because there is a substantial increase of the dipole moment of the transition state and of the product in relation to reactants, the solvent stabilizes both the transition state and the product. The free energy profile of this reaction is shown in Figure 3 for the reaction in the gas phase, apolar (toluene) and polar (acetonitrile) solvents. The solvent effect is much more important for the ion pair product, because the free energy of reaction goes from $9.0 \mathrm{kcal} \mathrm{mol}^{-1}$ (gas phase) to $-7.6 \mathrm{kcal} \mathrm{mol}^{-1}$ (acetonitrile), whereas the activation barrier decreases by $4.3 \mathrm{kcal} \mathrm{mol}^{-1}$.

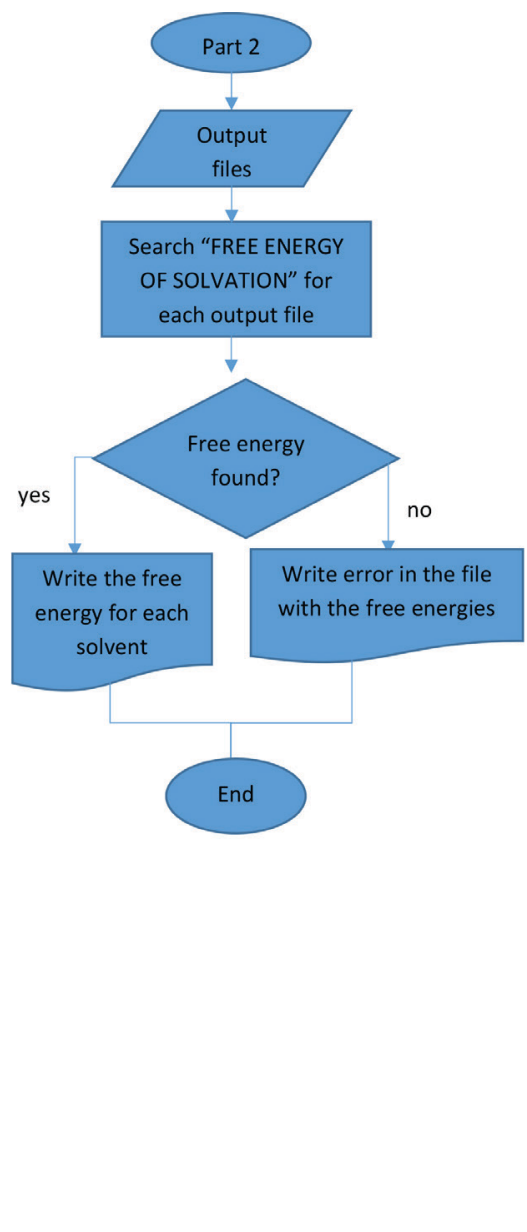

There is experimental data for this reaction for five different solvents: toluene, chloroform, tetrahydrofuran, acetone and acetonitrile. ${ }^{41}$ We have plotted the theoretical free energy barrier versus the experimental data, obtained from the experimental rate

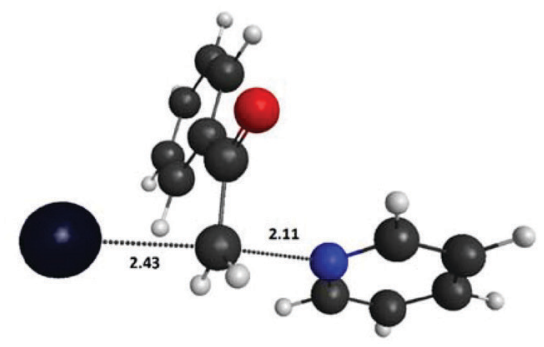

Transition state

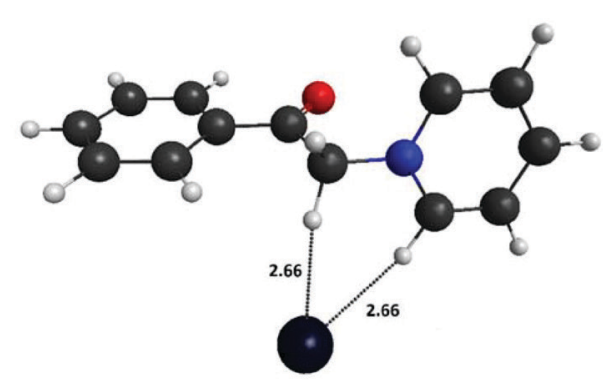

Product

Figure 2. Transition state and product of the reaction presented in Scheme 2 




Figure 3. Gibbs free energy profile for the investigated reaction in the gas phase, toluene and acetonitrile. Units in $\mathrm{kcal} \mathrm{mol}^{-1}$

constants, presented in Figure 4. It can be observed that the theoretical free energy barriers overestimate the experimental barriers by $4 \mathrm{kcal} \mathrm{mol}{ }^{-1}$. This deviation has two sources: the M08-HX method and the SMD model. Extensive tests on the performance of this functional for activation barriers have found a mean uncertain lower than $2 \mathrm{kcal} \mathrm{mol}^{-1}{ }^{49}$ In the case of the SMD model, the error in the barriers for anion-molecule reactions, using $\operatorname{CCSD}(\mathrm{T})$ method for electronic energy, reaches $3 \mathrm{kcal} \mathrm{mol}^{-1}$ in methanol as solvent. ${ }^{35}$ Consequently, while part of the error is due to the M08-HX method, we believe that the main source of error on these calculations can be attributed to the flaw of the continuum SMD model to describe accurately very polar structure, like the transition state of this reaction. However, the deviation is similar for each solvent, indicating a good correlation between theory and experiment, with $\mathrm{R}^{2}=0.80$ (coefficient of determination). Thus, the SMD model is able to predict correctly the trend in the reactivity.

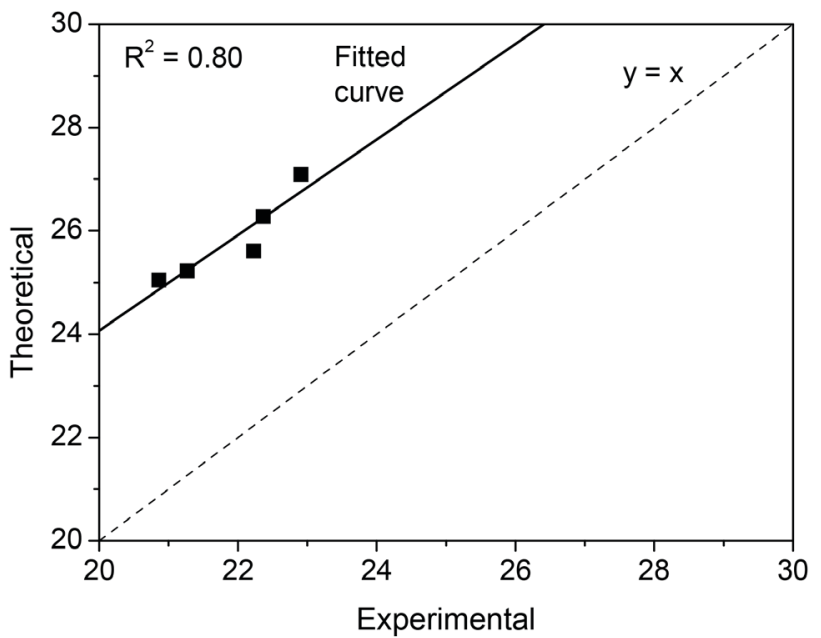

Figure 4. Theoretical versus experimental free energy of activation for the reaction in Scheme 2. Solvents toluene, chloroform, tetrahydrofuran, acetone, acetonitrile. Experimental data from ref. 41

The calculated barriers for all the 179 solvents are presented in the supporting information. We have chosen some solvents, reported by Struebing et al., as well as additional solvents, and presented the results in Table 1 . The free energy barriers calculated by
Struebing et al. is few kcal mol-1 lower than our calculated barrier, due to different level of theory used. Thus, we have compared the relative barriers and taken the toluene solvent as the reference. The reactivity order is the same as that reported by Struebing et al., from toluene to nitromethane. Those authors have found that nitromethane is the most effective solvent to accelerate the reaction. Our results point out this is not the case. Table 1 reports five solvents superior to nitromethane, based on SMD calculations. We have predicted that the most effective solvent is sulfolane, with a free energy barrier $0.62 \mathrm{kcal} \mathrm{mol}^{-1}$ lower than nitromethane. Considering the exponential dependence of the rate constant with $\Delta \mathrm{G}^{\ddagger}$, given by transition state theory (equation 1 ), this difference in $\Delta \mathrm{G}^{\ddagger}$ makes a significative effect on the conversion rate. Figure 5 shows the conversion of 2-bromoacetophenone to the product and a comparison between the nitromethane and sulfolane solvents, based on our calculated $\Delta \mathrm{G}^{\ddagger}$. To simulate the second order kinetics, we have used $0.40 \mathrm{~mol} \mathrm{~L}^{-1}$ for 2-bromoacetophenone and $0.80 \mathrm{~mol} \mathrm{~L}^{-1}$ for pyridine. We can see that sulfolane has a significative increase in the product formation in relation to nitromethane.

Table 1. Free energy of activation in different solvents for the reaction in Scheme $1^{\mathrm{a}}$

\begin{tabular}{lcccc}
\hline & $\begin{array}{c}\Delta \mathrm{G}^{\ddagger} \\
(\mathrm{CAMD})^{\mathrm{b}}\end{array}$ & $\begin{array}{c}\Delta \Delta \mathbf{G}^{\ddagger} \\
(\mathbf{C A M D})^{\mathbf{b}}\end{array}$ & $\begin{array}{c}\Delta \mathrm{G}^{\ddagger} \\
(\mathrm{SMD})^{\mathrm{c}}\end{array}$ & $\begin{array}{c}\Delta \Delta \mathbf{G}^{\ddagger} \\
(\mathbf{S M D})^{\mathbf{c}}\end{array}$ \\
\hline toluene & 25.36 & $\mathbf{0 . 0 0}$ & 27.09 & $\mathbf{0 . 0 0}$ \\
chlorobenzene & 23.46 & $\mathbf{- 1 . 9 0}$ & 25.93 & $\mathbf{- 1 . 1 6}$ \\
ethyl acetate & 23.33 & $\mathbf{- 2 . 0 3}$ & 25.85 & $\mathbf{- 1 . 2 4}$ \\
THF & 22.99 & $\mathbf{- 2 . 3 7}$ & 25.61 & $\mathbf{- 1 . 4 8}$ \\
acetone & 22.29 & $\mathbf{- 3 . 0 7}$ & 25.22 & $\mathbf{- 1 . 8 7}$ \\
acetonitrile & 21.99 & $\mathbf{- 3 . 3 7}$ & 25.05 & $\mathbf{- 2 . 0 4}$ \\
nitromethane & 21.84 & $\mathbf{- 3 . 5 2}$ & 24.90 & $\mathbf{- 2 . 1 9}$ \\
Formic acid & & & 24.90 & $\mathbf{- 2 . 1 9}$ \\
DMF & & & 24.84 & $\mathbf{- 2 . 2 5}$ \\
Ethylene glycol & & & 24.64 & $\mathbf{- 2 . 4 5}$ \\
DMSO & & & 24.61 & $\mathbf{- 2 . 4 8}$ \\
formamide & & & 24.43 & $\mathbf{- 2 . 6 6}$ \\
sulfolane & & & 24.28 & $\mathbf{- 2 . 8 1}$ \\
\hline
\end{tabular}

a - Units in kcal mol ${ }^{-1}$. Temperature of $25{ }^{\circ} \mathrm{C}$ and standard state of $1 \mathrm{~mol} \mathrm{~L}^{-1}$. $\mathrm{B}-$ Calculations by Struebing and co-workers. c-This work, based on PCM/ X3LYP/6-31(+)G(d) geometries, single point energy at M08-HX/def2-TZVPP level and solvation free energy at SMD/X3LYP/6-31G(d) level.

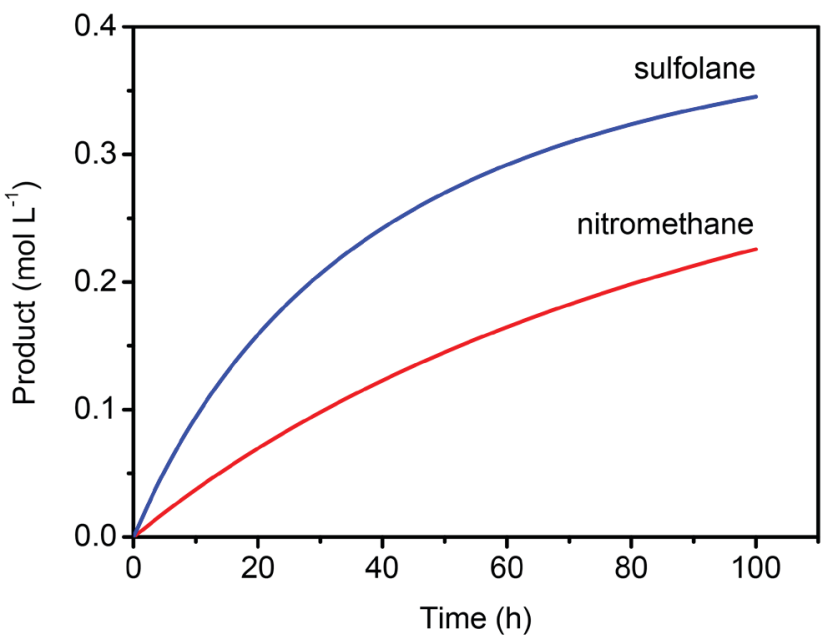

Figure 5. Formation of products based on SMD calculations in two solvents, using $0.40 \mathrm{~mol} \mathrm{~L}^{-1}$ of 2-bromoacetophenone and $0.80 \mathrm{~mol} \mathrm{~L}^{-1}$ of pyridine 
The approach used by Struebing et al. does not include sulfone, sulfoxide and amide groups. Thus, it excludes very import classes of solvents. Nevertheless, it includes ethylene glycol. The SMD calculation predicts that ethylene glycol is superior to nitromethane and the CAMD method was not able to catch this feature.

An important point to note is that the approach discussed in this work can be used for general study of chemical reactions, not only reaction rates. For example, the selectivity of the reaction can be controlled by the solvent. ${ }^{54,55}$ In special, organocatalyzed controlled enantioselectivity is a very active research field in the present time..$^{56-61}$ In the same direction, the thermodynamic of the reaction can be an important issue in the selectivity when the reaction $\Delta \mathrm{G}$ is close to zero. ${ }^{15}$ These properties may have a significative solvent effect, and the present approach is a viable method to test a high number of solvents (179 available in SMD) using modern workstations.

This report is related to our previous publication on fast solvent selection for extraction of chemicals (furfural, hydroxymethylfurfural and levulinic acid) from aqueous solution. ${ }^{50}$ Thus, we have shown that the procedure can be easily applied for solvent selection for chemical reactions. The accuracy of the predictions depends on the reliability of the SMD model, maybe the most widely used solvent model in the present time.

\section{CONCLUSION}

In summary, the present theoretical study makes an automated screening of solvents for the Menshutkin reaction in Scheme 2, through full calculation of the solvation free energy for 179 solvents using the SMD model. The automated procedure allows fast preparation of inputs and reading of outputs. We have found the sulfolane is the best solvent for this reaction and it outperforms the previously suggested nitromethane solvent, based on an approximation to the SMD model.

\section{SUPPLEMENTARY MATERIAL}

Complete table of the calculated free energies of activation is available online in pdf format and can be freely accessed at http://quimicanova.sbq.org.br.

\section{ACKNOWLEDGMENTS}

The authors thank the agencies CNPq and FAPEMIG for support.

\section{REFERENCES}

1. Reichardt, C.; Welton, T.; Solvents and Solvent Effects in Organic Chemistry, $4^{\text {th }}$ ed., Wiley-VCH Verlag GmbH \& Co. KGaA: Weinheim, Germany, 2011.

2. Diorazio, L. J.; Hose, D. R. J.; Adlington, N. K.; Org. Process Res. Dev. 2016, 20, 760.

3. Kokitkar, P. B.; Plocharczyk, E.; Chen, C.-C.; Org. Process Res. Dev. 2008, 12, 249.

4. Blumenthal, L. C.; Jens, C. M.; Ulbrich, J.; Schwering, F.; Langrehr, V.; Turek, T.; Kunz, U.; Leonhard, K.; Palkovits, R.; ACS Sustainable Chem. Eng. 2016, 4, 228.

5. Xiong, R.; Miller, J.; León, M.; Nikolakis, V.; Sandler, S. I.; Chem. Eng. Sci. 2015, 126, 169.

6. Klamt, A.; Eckert, F.; Arlt, W.; Annu. Rev. Chem. Biomol. Eng. 2010, 1, 101.

7. Delaney, J. S.; Drug Discovery Today 2005, 10, 289.

8. Prat, D.; Wells, A.; Hayler, J.; Sneddon, H.; McElroy, C. R.; AbouShehada, S.; Dunn, P. J.; Green Chem. 2016, 18, 288.
9. Isoni, V.; Wong, L. L.; Khoo, H. H.; Halim, I.; Sharratt, P.; Green Chem. 2016, $18,6564$.

10. Pena-Pereira, F.; Kloskowski, A.; Namiesnik, J.; Green Chem. 2015, 17, 3687.

11. Truhlar, D. G.; Pliego Jr, J. R. In Continuum Solvation Models in Chemical Physics: From Theory to Applications; Mennucci, B., Cammi, R., eds.; John Wiley \& Sons: Chippenham, Wiltshire, Great Britain, 2007, p. 338.

12. Soteras, I.; Blanco, D.; Huertas, O.; Bidon-Chanal, A.; Luque, F. J. In Continuum Solvation Models in Chemical Physics: From Theory to Applications; Mennucci, B., Cammi, R., eds.; John Wiley \& Sons: Chippenham, Wiltshire, Great Britain, 2007, p. 323.

13. Westphal, E.; Pliego Jr, J. R.; J. Phys. Chem. A 2007, 111, 10068.

14. Orlandi, M.; Ceotto, M.; Benaglia, M.; Chem. Sci. 2016, 7, 5421.

15. Peng, Q.; Duarte, F.; Paton, R. S.; Chem. Soc. Rev. 2016, 45, 6093.

16. Hansen, N.; van Gunsteren, W. F.; J. Chem. Theory Comput. 2014, 10, 2632.

17. Acevedo, O.; Jorgensen, W. L.; Wiley Interdiscip. Rev. Comput. Mol. Sci. 2014, $4,422$.

18. Acevedo, O.; Jorgensen, W. L.; Acc. Chem. Res. 2010, 43, 142.

19. Klamt, A.; Mennucci, B.; Tomasi, J.; Barone, V.; Curutchet, C.; Orozco, M.; Luque, F. J.; Acc. Chem. Res. 2009, 42, 489.

20. Curutchet, C.; Orozco, M.; Luque, F. J.; Mennucci, B.; Tomasi, J.; J. Comp. Chem. 2006, 27, 1769.

21. Tomasi, J.; Mennucci, B.; Cammi, R.; Chem. Rev. 2005, 105, 2999.

22. Cramer, C. J.; Truhlar, D. G.; Acc. Chem. Res. 2008, 41, 760.

23. Marenich, A. V.; Cramer, C. J.; Truhlar, D. G.; J. Chem. Theory Comput. 2012, 9, 609.

24. Marenich, A. V.; Cramer, C. J.; Truhlar, D. G.; J. Phys. Chem. B 2009, 113, 6378.

25. Klamt, A.; J. Phys. Chem. 1995, 99, 2224.

26. Klamt, A.; Schuurmann, G.; J. Chem. Soc., Perkin Trans. 2 1993, 799.

27. Miertus, S.; Scrocco, E.; Tomasi, J.; Chem. Phys. 1981, 55, 117.

28. Hellweg, A.; Eckert, F.; AIChE Journal 2017, 63, 3944.

29. Tomasi, J. In Continuum Solvation Models in Chemical Physics: From Theory to Applications; Mennucci, B., Cammi, R., eds.; John Wiley \& Sons: Chippenham, Wiltshire, Great Britain, 2007, p. 1.

30. Cammi, R. In Continuum Solvation Models in Chemical Physics: From Theory to Applications; Mennucci, B., Cammi, R., eds.; John Wiley \& Sons: Chippenham, Wiltshire, Great Britain, 2007, p. 82.

31. Luque, F. J.; Curutchet, C.; Munoz-Muriedas, J.; Bidon-Chanal, A.; Soteras, I.; Morreale, A.; Gelpi, J. L.; Orozco, M.; Phys. Chem. Chem. Phys. 2003, 5, 3827.

32. Pliego Jr, J. R.; Quim. Nova 2006, 29, 535.

33. Marenich, A. V.; Cramer, C. J.; Truhlar, D. G.; J. Phys. Chem. B 2009, $113,4538$.

34. Guerard, J. J.; Arey, J. S.; J. Chem. Theory Comput. 2013, 9, 5046.

35. Silva, N. M.; Deglmann, P.; Pliego, J. R.; J. Phys. Chem. B 2016, 120, 12660.

36. Miguel, E. L. M.; Santos, C. I. L.; Silva, C. M.; Pliego Jr, J. R.; J. Braz. Chem. Soc. 2016, 27, 2055.

37. Zanith, C. C.; Pliego Jr, J. R.; J. Comput. Aided Mol. Des. 2015, 29, 217.

38. Lisboa, F. M.; Pliego, J. R.; J. Mol. Model. 2018, 24, 56.

39. Silva, C. M.; Silva, P. L.; Pliego, J. R.; Int. J. Quant. Chem. 2014, 114, 501.

40. Pliego Jr, J. R.; Riveros, J. M.; Chem. Eur. J. 2002, 8, 1945.

41. Struebing, H.; Ganase, Z.; Karamertzanis, P. G.; Siougkrou, E.; Haycock, P.; Piccione, P. M.; Armstrong, A.; Galindo, A.; Adjiman, C. S.; Nat. Chem. 2013, 5, 952.

42. Struebing, H.; Obermeier, S.; Siougkrou, E.; Adjiman, C. S.; Galindo, A.; Chem. Eng. Sci. 2017, 159, 69. 
43. Xu, X.; Zhang, Q.; Muller, R. P.; Goddard III, W. A.; J. Chem. Phys. 2005, 122, 014105 .

44. Silva, C. M.; Dias, I. C.; Pliego, J. R.; Org. Biomol. Chem. 2015, 13, 6217.

45. Su, P.; Li, H.; J. Chem. Phys. 2009, 130, 074109.

46. Zhao, Y.; Truhlar, D. G.; J. Chem. Theory Comput. 2008, 4, 1849.

47. Weigend, F.; Ahlrichs, R.; Phys. Chem. Chem. Phys. 2005, 7, 3297.

48. Zheng, J. J.; Xu, X. F.; Truhlar, D. G.; Theor. Chem. Acc. 2011, 128 , 295.

49. Mardirossian, N.; Head-Gordon, M.; J. Chem. Theory Comput. 2016, 12, 4303.

50. Dalessandro, E. V.; Pliego Jr, J. R.; J. Braz. Chem. Soc. 2018, 29, 430.

51. https://ufsj.edu.br/lqtc/softwares.php, acessada em dezembro de 2017.

52. Gordon, M. S.; Schmidt, M. W. In Theory and Applications of Computational Chemistry; Dykstra, C. E., Frenking, G., Kim, K. S., Scuseria, G. E., eds.; Elsevier: Amsterdam, 2005, p. 1167.
53. Schmidt, M. W.; Baldridge, K. K.; Boatz, J. A.; Elbert, S. T.; Gordon, M. S.; Jensen, J. H.; Koseki, S.; Matsunaga, N.; Nguyen, K. A.; Su, S.; Windus, T. L.; Dupuis, M.; Montgomery Jr, J. A.; J. Comp. Chem. 1993, $14,1347$.

54. Pliego Jr, J. R.; Piló-Veloso, D.; J. Phys. Chem. B 2007, 111, 1752.

55. Lee, J.-W.; Oliveira, M. T.; Jang, H. B.; Lee, S.; Chi, D. Y.; Kim, D. W.; Song, C. E.; Chem. Soc. Rev. 2016, 45, 4638.

56. Sunoj, R. B.; Acc. Chem. Res. 2016, 49, 1019.

57. Jindal, G.; Kisan, H. K.; Sunoj, R. B.; ACS Catal. 2015, 5, 480.

58. Lam, Y.-h.; Grayson, M. N.; Holland, M. C.; Simon, A.; Houk, K. N.; Acc. Chem. Res. 2016, 49, 750.

59. Martins, E. F.; Pliego Jr, J. R.; J. Mol. Catal. A: Chem. 2016, 417, 192.

60. Martins, E. F.; Pliego, J. R.; ACS Catal. 2013, 3, 613.

61. Braga, A. L.; Lüdtke, D. S.; Schneider, P. H.; Andrade, L. H.; Paixão, M. W.; Quim. Nova 2013, 36, 1591. 